\title{
Biological Therapy
}

National Cancer Institute

\section{Source}

National Cancer Institute. Biological Therapy. NCI Thesaurus. Code C15187.

A type of treatment that uses substances derived from or made by living organisms to treat disease; this includes both naturally occurring and synthetic products. 